\title{
Fairy Tale ContainerasaContinuous Story Telling Media
}

\author{
RetnoPurwanti $M^{1}$ and Yunisa Fitri Andriani ${ }^{2}$ \\ ${ }^{1}$ Faculty of Design and Technology, Universitas Pembangunan Jaya, Tangsel, Indonesia \\ ${ }^{1}$ retno.purwanti@upj.ac.id, ${ }^{2}$ yunisa.fitri@upj.ac.id
}

\begin{abstract}
Basically, fairy tales is an art of speaking to convey moral values of virtue in local wisdom that are conveyed orally and using the help of the media. Because not everyone has a good capability in speaking verbally, so sometimes a tool is needed as a medium to tell stories. Tin containers as one of material that is not easily recycled to be chosen in an attempt to infuse awareness for children to keep the effort of the environment in a creative way.The purpose of this research is to develop the imaginary potential for any children to know how big the influence of the tools of the tin container in developing the fabled any imaginary primary school student, especially by storytelling.By using the visual language experimentof wimbamethods of reading a children's drawing, this researchexpecting those tin containers could be an alternative educational tools for a storytelling media to develop creativity in a fun way.
\end{abstract}

Keywords: fairy tale, local wisdom, visual language,continuousart

\section{INTRODUCTION}

As a multicultural country, Indonesia has abundant traditions and local wisdom values which are needed to be preserved as the negative influences come from outside. The local values can protect the good life of Indonesian people in today's globalization and information era. Universally, fairy tales have become the most effective communicating media[1]. If the western world refers to an epic narration of the land conqueror - colony land by the kings, literature development in the eastern world influenced by tradition in verbal as a fairy tale to deliver an implied message, including local culture values inside. One way to introduce the values of local wisdom is through the nusantarafolklore to elementary school students as an effort to establish noble character, the introduction of norms and ethics as a form of fortification against the negative effects of globalization[2]. The nusantara folklore serves to convey moral teachings (educate), and also entertain, besides that it also functions as a teaching of good moral values, develops the imagination of children, adds insight into children, enhances children's creativity, draws children closer to their parents and instills a sense of empathy for the surrounding environment Folklore as the art of Storytelling speech that is able to awaken the imagination as a basic for children's creativity and intelligence is 
expected to become an intellectual legacy through a touch of innovation and technology[3]. Since childhood, an individual has been infused with the cultural values of his community, so that the concepts have been rooted in his mentality and then difficult to replace with others in a short time[4]. In the context of artifacts as a form of culture, containing cultural values, including the value of function, meaning and symbol. Visual language has been employed from earliest pre history to the present and are used in almost every human endeavor[5]. The most fundamental aims is to gain a better understanding of how visual language can be naturally classified and how they can be naturally and spesified concisely specified. A more applied aim of visual language research is to understand what makes one visual language which better than another and so to develop guidelines for the design of new visual language. The compound 'folk' + 'lore' appeared in the twentieth century, where 'lore' means the 'act of teaching, instruction, education and lesson[6]. Folklore indicates popular culture, 'the set of customs, legends, proverbs, artistic expressions in general, preserved through oral and visual tradition by a people or population group' [7].

\section{METHOD}

Sequential art is a collection of works of art with continuity between one another, both image and story.Sequential art is a proven art (next to each other or close together) Sequential art is formed by using a sequential format so as to bring up a story or purpose[8]. This Fine Language is a way of 'reading' pictures, from various images. In the language of the image there are wimbas, in the wimba there is the content of wimba and way of wimba. The content of the wimba is a picture contained in the wimba, and the way the wimba is how the wimba is drawn and can be told. Through the 'science' is the original image that is beginning to be understood and retold as teaching materials or materials of scientific art for future studies, about the image of traditions and modern drawings[9].

This research uses experimental methods with a theoretical approach to visual language, where this theory uses a theory called Wimba, Wimba way, connecting technique and grammar of expression. Visual language is a picture or visual creation that tells a story through visual language so that we could read and understand children's pictures, including imaginative messages they gave. The method they use is Space Time Plane (RWD), where space and time are not separated. In this method a story that is poured into the form of images also hasa certain order, like language, which uses grammar rules. The image system covers a broad range of meanings of either the visible or the imaginary. The imaging of the data from a story, and perhaps also some representative pictures, is called the wimba. A wimbais divided into two parts, namely the content and the wimba manner (method). For example, Wimbacontent are objects that are drawn, Translating the wimbainto a story is done by following the procedures of the expression system (tataungkapan). The expression system has two aspects, namely the inner expression system - a method to translate the wimbaand the wimbamanner into single-frame images - and the external expression, which is an image transfer technique[10]. 


\section{RESULT AND DISCUSSION}

\subsection{Formulationofthe Problem :}

Storytelling media from time after time experienced a lot of changes. Technology development related to the discovery of industrial papers and printers causes literature production costs a lot affordable make speaking verbally shifts towards writing culture. but the availability of paper raw materials which began to thin out as a result of the increasingly reduced forest land for settlements, plus the emergence of digital technology that carries a new culture into an electronic book (e-book) again changed the way story telling.However, which is interesting to be observed on storytelling is that they always look interesting to children, one of the reason is that fairy tales give them imaginary thoughts for the children, where childhood was known to be a phase full of imagination.

\subsection{Research ObjectivesandBenefits:}

Starting to find alternatives story telling media besides books, the choice fell on the used cans biscuit packaging material which was considered unique and had several advantages. The choice of cans material as durable packaging material as well as the effort to reuse and recycle canspackaging becomes something useful.How to recycle non-degradable waste such as used tin containers into useful productssuch as visual aids education, in the form of sustainable art and design as a fairy tale media on the sides and surface of the can. Packaging and its functions may play a significant role for the amount of food waste in households. Participants with high environmental consciousness waste less food and are more observant of packaging and its role in food waste reduction[11].

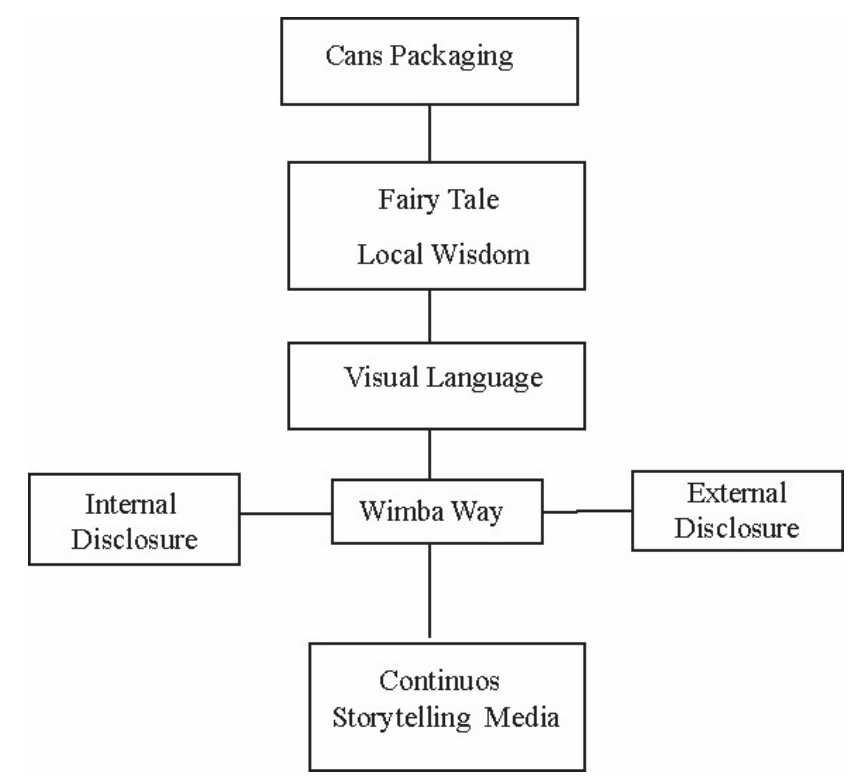

figure1: The scheme of think 
The research is using experiment of wimba methods by using an internal (Tata UngkapDalam) and external (Tata UngkapLuar) disclosure system of Space Time Plane (RWD)from a visual language that opens the gate of imagination for children. The aim that the cans container not just in the form of decoration, we apply fairy tales that containing many moral values from local wisdom.

With a 3D shape in the form of a short cylinder measuring $\mathrm{r}=7 \mathrm{~cm} \mathrm{~h}=8 \mathrm{~cm}$ high this tin container is considered to have fulfilled several requirements as educational aids, 1) educational requirements, 2) technical requirements, 3) aesthetic conditions with the following description;educational requirements adapted to the goals and educational programs that encourage students' imagination and creativity,technical requirements in the form of the right shape and size, so didn't cause misconceptions or perceptions, multipurpose, made with materials that are easily obtained or used materials, safe (does not contain elements that can endanger the safety of children) and Easy to use, adding to the child's pleasure to experiment and explore.Aesthetic requirements include an ergonomic shape that is easy for children to carry, size harmony, and attractive color combinations[12].

From several studies related to the utilization of waste materials, not many process materials of packaging cans, and generally only reused as containers with decorative decoration. Through the experiment of visual language this can packaging can be functioned as a media story telling to introduce the values of local wisdom by visual tales. The visual style of Space Time Plane (RWD) that is similar to a child's drawing technique makes it feel familiar and become a special attraction for them. The media not only can entertain but to have value education about the moral of fairy stories who is on the surface cans. Through the media is all the students can learn how to process waste of material that did not easily unraveled into products that come in handy as an effort to concern about the environment.

The new Graphic Design curriculum asserts that designers' decisions have an impact on the planet, and understanding that impact and accepting responsibility for one's actions, contributes to the moral and ethical condition of the educated professional. Topics include investigation of issues of design responsibility, sustainable practices, cultural awareness including equality and tolerance, as well as the application of knowledge in response to the physical, cultural, and social human factors that shape design solutions and impact civic and ecological attitudes. For the profession of graphic design to truly develop an understanding of sustainability, there needs to be a basic philosophy considering the importance of sustainability for graphic design and the environment[13]. This basic philosophy needs to inspire graphic designers to ask, "How can we make this project ecologically friendly so as to minimize or eliminate the impact on the natural environment?" so not just using ecologycal buzzword. Base on that philosophy, we try to apply them into our project as Fairy Tale Container as a Continuous Story Telling Media that we called "kalengdongeng" What we meant by continuous art or design, especially on a recycling product is an effort to hold an object as long as it takes by changing its shape or changing its function until then ends up in the waste[14]. One of the ways is to divert this tin container waste that it's not only for decorating purposes with no meaning, however, into a more useful as a storytelling media and to become an educational tool to introduce local fairy tales trough the fairytale container product. 


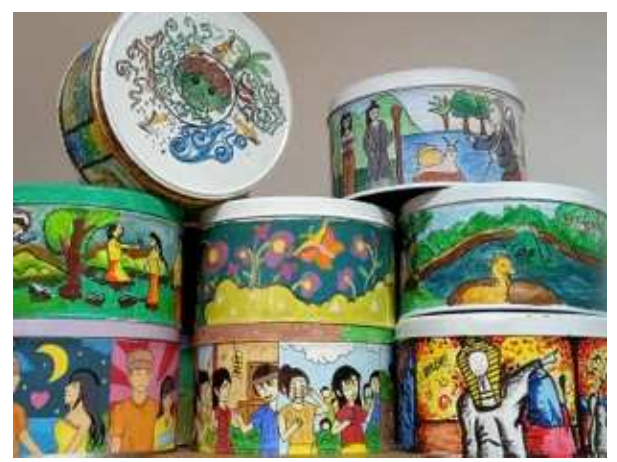

Figure 2: Results of applying visual language on tin containers as a storytelling media

By applying techniques to draw in Space Time Plane (RWD) or without perspective, many found in a child's drawing about many stories of various Nusantara tales displayed at the sides of the container. To express fairy stories using Wimba way comes with two kinds of approaches which are the inside expression and external expression. The uniqueness of the internal expression's way is where every story is expressed and drawn in only one space which is the top of the can. Meanwhile, the sides of the can are expressed by drawing the story in order on the sides of then container frame by frame, almost like a comic. Other than showing how unique the media to tell the tale, this fable can also have a story synopsis paper inside of the can for every choice of fable that is available. This is for making parents or teachers easy to tell the story to the children.

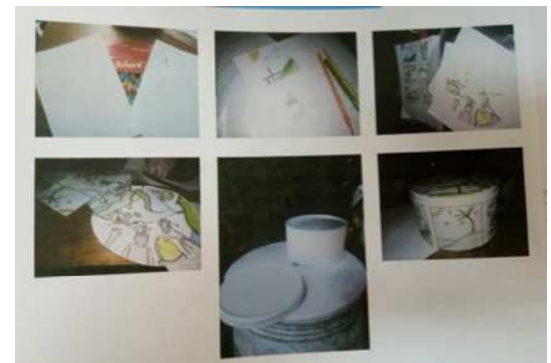

figure 3 : Work process of the fairy tale containers

The making process of the container started with a story concept arrangement verbally to visually on the paper, this concept is divided into two which is the top of the container lid and drawn with internal expression technique which will visualize the whole story in one frame including the movement the story characters do on the story, this technique will become the storyline, its just with a visual way and not a verbal way. Meanwhile, the concept to apply to the sides of the container is using an external expression of the connecting technique like a depiction of a visual comic in general, which is lined in order per scene. The depiction of an external expression is similar to a storyboard without a duration. After this visual concept is finished, the next step will be moving the finished visual object on the lid of the container. This process can be done by manually drawing the object directly on the lid starting from outlining and into coloring or finished with help by printing digital media. 

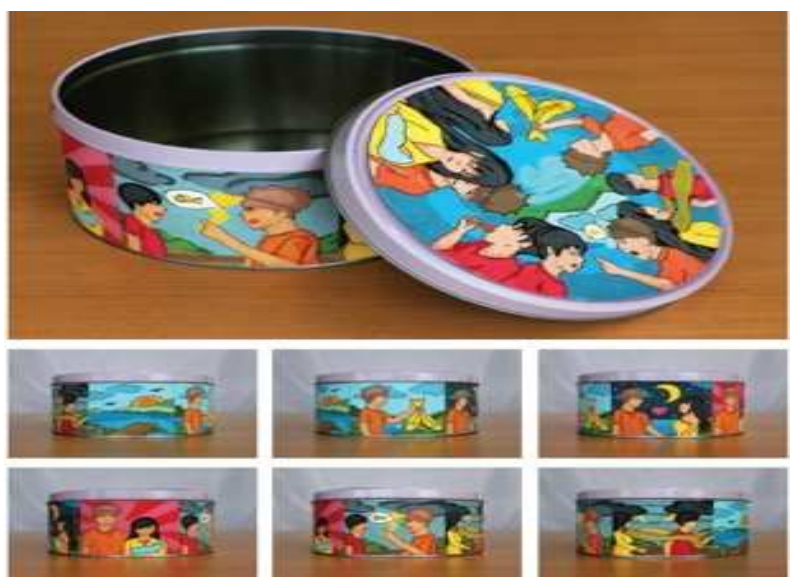

figure 4 : Fairy Tale Can with Danau Toba story from North Sumatera

The Wimba way (a way to draw an object) can be seen on the top of the lid drawn with the internal expression which illustrating the whole story in one frame, we also use child drawing approach with a technique called the flat technique where all objects are seen in the position from above in flat. Including characters and scenes that illustrate movement. Moving objects are shown by multiplying like on Picture 4 on the top of the lid. It is shown that the main character Toba is holding two fishes, however, the idea is that the fish is flopping left and right. As well as the child as a character called Samosir, it looks like there are two-person on the frame but its the way to show that the character moves. Meanwhile, the sides of the container are drawn frame-by-frame like a comic.

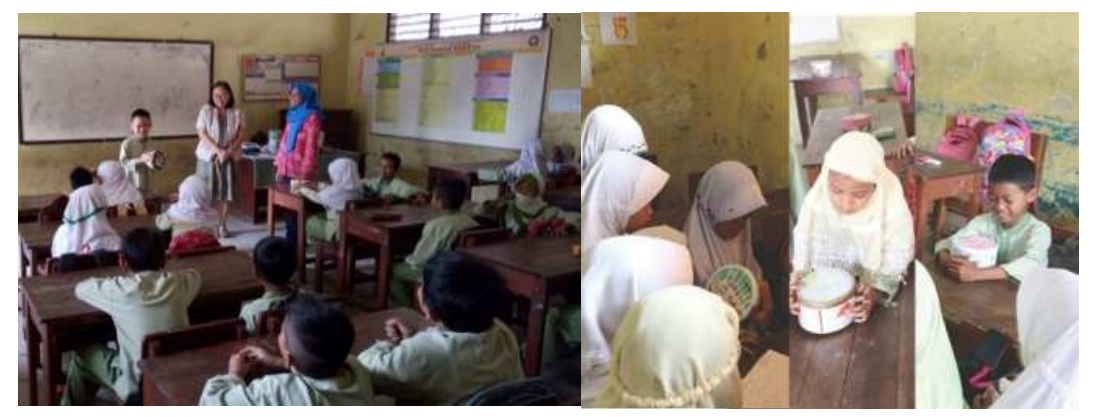

figure 5: Fairy Tale Can trial in SDN SawahBaru 01 Ciputat, Tangerang Selatan figure 6: Enthusiast and respond from elementary students about the fairy tale can 


\section{CONCLUSION}

From our focus group discussion (FGD) with Bahasa Indonesia teacher in SDN 01 SawahBaru, fairy tale container product can be used to deliver moral messages and to instill values of virtue to the children through visualization of a verbal fairy tale also to show more continuous art creation like this one. Most kids stated they would prefer the fairy tale container because they liked the colorful visual appearance and they also did not appear with texts which made regular storytelling books boring to them. Based on the exposure above, conclusions can be drawn that attractions are made from this fairy tale container creation is the display of visualization on a tin container media which makes them unique and the way to draw unusual storyline objects (with a Wimba way)

\section{REFERENCES}

[1]. Sugiyo, Rukiyati, and L. AndrianiPurwastuti. "Local Wisdom-Based Character Education Model in Elementary School in Bantul Yogyakarta Indonesia." Sino-US English Teaching 14.5,pp.299308, 2017.

[2]. P.Martin. "The Written World: The Power of Stories to Shape People". History, Civilization. Harvard University. 2018

[3]. Suarta, I. "PerananDongengLokalDalamMemperkayaLiterasiNasional." Seminar Nasional "PenanamanNilai-nilaiPendidikanmelaluiSeniBudaya Nusantara" pp.41-53, 2019.

[4]. Prayoga, Randy Widi, HeriSuwigyo, and TitikHarsiati. "Nilai-nilaiKearifanLokalpadaCerita Rakyat Nusantara." Seminar NasionalTeknologiPembelajarandanPendidikanDasar" 2017.

[5]. Wardani, LaksmiKusuma. "Fungsi, maknadansimbol." ProsidingSeminar JelajahArsitekturNusantara. 2010.

[6]. Marriott, Kim, and Bernd Meyer, eds. Visual language theory. Springer Science \& Business Media, 2012.

[7]. Quental,Joana."Searching for a Common Identity: The folklore Interpreted through illustration" Journal of Illustration. 1.1, 2014.

[8]. Mataram, Sayid. "TinjauanWayangBebersebagai Sequential Art." Canthing 2.2, 2014.

[9]. Tabrani, Primadi. "Prinsip-PrinsipBahasaRupa." JurnalBudaya Nusantara 1.2.pp 173-195, 2018.

[10]. Ningsih, Yosepin Sri, John Martono, and ZainiRais. "I La Galigo Folklore Illustration on Textile Media." Journal of Visual Art and Design 6.1 pp1-8. 2014.

[11]. Williams, Helén, et al. "Reasons for household food waste with special attention to packaging." Journal of cleaner production 24, pp.141-148, 2012.

[12]. Sulastri, YayuLaila, AldilaRahma, and LukiLuqmanul Hakim. "IbMPembuatanAlatPermainanEdukatif (APE) Ramah AnakBagi Guru Paud di Kota Bandung." JurnalPengabdianKepadaMasyarakat7.2 pp84-91.2017.

[13]. Vessella, Sue, and Behnoush McKay. "A Case Study of an Innovative Graphic Design Curriculum Focusing on Social Responsibility." Design Principles \& Practice: An International Journal 5.5 2011.

[14]. Graham, M. Lisa. "Towards a More Sustainable Graphic Design Philosophy,"International Journal of the Arts in Society, Vol. 6 Issue 5, p169-176. 8p. 2012. 